\title{
Medication regimen complexity in ambulatory older adults with heart failure
}

\author{
This article was published in the following Dove Press journal: \\ Clinical Interventions in Aging \\ 12 April 2017 \\ Number of times this article has been viewed
}

\author{
Michael R Cobretti' \\ Robert L Page II ${ }^{2}$ \\ Sunny A Linnebur ${ }^{2}$ \\ Kimberly M Deininger ${ }^{1}$ \\ Amrut V Ambardekar ${ }^{3}$ \\ JoAnn Lindenfeld ${ }^{4}$ \\ Christina L Aquilante' \\ 'Department of Pharmaceutical \\ Sciences, ${ }^{2}$ Department of Clinical \\ Pharmacy, Skaggs School of Pharmacy \\ and Pharmaceutical Sciences, \\ University of Colorado, Aurora, CO, \\ ${ }^{3}$ Division of Cardiology, School of \\ Medicine, University of Colorado, \\ Aurora, CO, ${ }^{4}$ Advanced Heart Failure \\ and Cardiac Transplant Program, \\ Vanderbilt Heart and Vascular \\ Institute, Nashville, TN, USA
}

Purpose: Heart failure prevalence is increasing in older adults, and polypharmacy is a major problem in this population. We compared medication regimen complexity using the validated patient-level Medication Regimen Complexity Index (pMRCI) tool in "young-old" (60-74 years) versus "old-old" (75-89 years) patients with heart failure. We also compared pMRCI between patients with ischemic cardiomyopathy (ISCM) versus nonischemic cardiomyopathy (NISCM). Patients and methods: Medication lists were retrospectively abstracted from the electronic medical records of ambulatory patients aged 60-89 years with heart failure. Medications were categorized into three types - heart failure prescription medications, other prescription medications, and over-the-counter (OTC) medications - and scored using the pMRCI tool.

Results: The study evaluated 145 patients ( $n=80$ young-old, $n=65$ old-old, $n=85$ ISCM, $\mathrm{n}=60$ NISCM, mean age $73 \pm 7$ years, $64 \%$ men, $81 \%$ Caucasian). Mean total pMRCI scores (32.1 \pm 14.4 , range 3-84) and total medication counts (13.3 \pm 4.8 , range $2-30)$ were high for the entire cohort, of which $72 \%$ of patients were taking eleven or more total medications. Total and subtype pMRCI scores and medication counts did not differ significantly between the youngold and old-old groups, with the exception of OTC medication pMRCI score $(6.2 \pm 4$ young-old versus $7.8 \pm 5.8$ old-old, $P=0.04)$. With regard to heart failure etiology, total pMRCI scores and medication counts were significantly higher in patients with ISCM versus NISCM (pMRCI score $34.5 \pm 15.2$ versus $28.8 \pm 12.7, P=0.009$; medication count $14.1 \pm 4.9$ versus $12.2 \pm 4.5, P=0.008$ ), which was largely driven by other prescription medications.

Conclusion: Medication regimen complexity is high in older adults with heart failure, and differs based on heart failure etiology. Additional work is needed to address polypharmacy and to determine if medication regimen complexity influences adherence and clinical outcomes in this population.

Keywords: medication complexity, heart failure, elderly, geriatric, aged

\section{Introduction}

Over 5.7 million Americans have been diagnosed with heart failure, and with the aging population, this number is expected to increase to 8 million by $2030 .{ }^{1-3}$ Heart failure is the most common diagnosis among hospitalized patients 65 years of age and older and the leading cause of readmissions in the Medicare population. ${ }^{4-6}$ Accompanying the increasing prevalence of heart failure in older adults is the high burden of treatment, which grows in complexity as the disease progresses and exacerbations occur. ${ }^{7,8}$ Older adults with heart failure also have numerous noncardiac comorbidities (eg, diabetes, chronic pulmonary disease, depression, anemia, chronic kidney disease), which further complicate clinical care and amplify treatment burden. ${ }^{9-11}$

Previous data suggest that on average, patients with heart failure take 6.8 prescription medications per day, resulting in 10.1 doses per day, not including over-the-counter
Correspondence: Christina L Aquilante Skaggs School of Pharmacy and Pharmaceutical Sciences, University of Colorado, 12850 East Montview Boulevard - mail stop C238,

Aurora, CO 80045, USA

$\mathrm{Tel}+\mathrm{I} 3037246126$

$\mathrm{Fax}+\mathrm{I} 3037246149$

Email christina.aquilante@ucdenver.edu hereby accept the Terms. Non-commercial uses of the work are permitted without any further permission from Dove Medical Press Limited, provided the work is properly attributed. For permission for commercial use of this work, please see paragraphs 4.2 and 5 of our Terms (https://www.dovepress.com/terms.php). 
(OTC) or complementary and alternative medications. ${ }^{12}$ As a result, polypharmacy (often defined as the use of five or more medications) is a pervasive problem in this population, particularly in older adults. ${ }^{12-16}$ Considering this high medication burden, it is not surprising that medication nonadherence ranges from $40 \%$ to $60 \%$ in heart failure patients. ${ }^{5,17}$ Poor adherence to heart failure medications is associated with deleterious clinical consequences and is a major cause of hospital readmissions. ${ }^{15,17-21}$ A better understanding of factors that may contribute to medication nonadherence, such as medication regimen complexity, is urgently needed, particularly in the elderly population.

"Medication regimen complexity" is a term used to describe multiple characteristics of a patient's drug regimen, beyond just the number of medications. ${ }^{22}$ It includes such factors as number of doses per day, number of units per dose, dosage forms, and additional instructions (eg, take with food). ${ }^{22}$ High medication regimen complexity has been associated with medication nonadherence, poor quality of life, and increased health-resource utilization (eg, hospital readmissions). ${ }^{23-27}$ The Medication Regimen Complexity Index (MRCI) was a tool developed and validated by George et al in patients with chronic obstructive pulmonary disease to measure prescription medications associated with that disease. ${ }^{22}$ The tool was subsequently expanded and validated by Libby et al to include all medications in a patient's drug regimen (ie, disease state-specific, other prescription, and OTC), which is often referred to as patient-level MRCI (pMRCI). ${ }^{28,29}$ The pMRCI tool has been used to quantify medication regimen complexity in numerous patient populations, such as geriatric depression; hospitalized elderly; residents in long-term care facilities; hospitalized patients with heart failure; heart, kidney, and liver transplants; HIV; hypertension; diabetes; and dialysis, among others. ${ }^{24,28-44}$

Although heart failure is a leading discharge diagnosis in older adults and polypharmacy is common in patients with heart failure, to the best of our knowledge medication regimen complexity has not been evaluated in the ambulatory setting for this population. Therefore, the purpose of our study was to quantify systematically medication regimen complexity in ambulatory older adults with heart failure using the pMRCI tool. The primary objective was to compare medication regimen complexity in patients with heart failure stratified by age: young-old (60-74 years of age) versus old-old (75-89 years of age). We hypothesized that medication complexity would be higher in the old-old versus the young-old patients, due to progression of heart failure, increasingly impaired physiologic function, and the presence of multiple comorbidities. The secondary objective was to compare medication regimen complexity in ambulatory older adults based on heart failure etiology, ie, ischemic cardiomyopathy (ISCM) versus nonischemic cardiomyopathy (NISCM).

\section{Materials and methods \\ Study design and population}

This cross-sectional study consisted of a retrospective electronic medical record review of men and women 60-89 years of age with any clinical diagnosis of heart failure, as reported in the health record. Included patients were required to have had at least one visit at the University of Colorado Hospital Advanced Heart Failure Outpatient Clinic between October 2014 and August 2015. This time frame was chosen to represent the most contemporary heart failure treatment strategies at the time of the study. Patients were excluded if they were 59 years of age and younger, 90 years of age and older, or did not have a clinical diagnosis of heart failure. Patients were also excluded if they had a history of solid organ transplant or HIV, as these could be potential confounders due to known high medication regimen complexity. The study protocol, including a full waiver of consent, was reviewed and approved by the Colorado Multiple Institutional Review Board. Standard-of-care clinical data were extracted from the electronic medical record and recorded in a deidentified fashion for this retrospective study.

\section{Medication coding}

Deidentified medication lists and patient-demographic data were extracted from University of Colorado Hospital electronic medical records. Medications were grouped into three categories: 1) disease-specific (heart failure-related) prescription medications, 2) other prescription medications, and 3) OTC medications. Prescription medications identified as disease-specific consisted of ACE inhibitors or angiotensinreceptor blockers, $\beta$-blockers (eg, carvedilol, metoprolol succinate, bisoprolol), diuretics (eg, furosemide), aldosterone antagonists (eg, spironolactone, eplerenone), digoxin, vasodilators (eg, hydralazine, isosorbide mononitrate or dinitrate), intravenous inotropes (eg, dobutamine or milrinone), intravenous vasodilators (eg, nitroglycerin or nitroprusside), and intravenous vasopressors (eg, norepinephrine, dopamine, or epinephrine). ${ }^{7}$ Examples of other prescription medications were statins, antiarrhythmics, potassium supplements, anticoagulants, antihypertensive agents not specifically indicated for heart failure (eg, atenolol), antidepressants, antianxiolytics, sedative hypnotics, antidiabetic agents, 
gout medications, thyroid supplements, opioid or nonopioid analgesics, and asthma or chronic obstructive pulmonary disease medications. Examples of OTC medications were multivitamins, laxatives, calcium supplements, aspirin, fish oils, and herbal products.

Medications were counted, and dosage formulations, frequencies, and additional directions were entered into an electronic pMRCI tool (Microsoft Access Database), which automatically calculated pMRCI scores. ${ }^{28}$ The electronic pMRCI tool is freely available at: http://www.ucdenver. edu/academics/colleges/pharmacy/Research/researchareas/ Pages/MRCTool.aspx. An overall pMRCI score was calculated for each patient, along with subscores for each medication type, ie, heart failure prescription medication, other prescription medication, and OTC medication. The electronic pMRCI tool consisted of three sections: dosage forms, dosage frequencies, and additional directions. A weight of 1 was given to each dosage form of "tablet/capsule" and a frequency of once-daily dosing. Higher weights were assigned relative to the increased level of difficulty of administration (eg, other dosage forms, other frequencies, and additional instructions). In many patients, medications were encountered that could be categorized as both prescription and OTC agents (eg, omeprazole $20 \mathrm{mg}$ ). Since most patients in this study were eligible for Medicare Part D prescription coverage and a majority of plans covered products deemed both prescription and OTC, these products were consistently coded under the "other prescription medication" category. Micromedex Solutions (Truven Health Analytics, Ann Arbor, MI, USA) and Facts \& Comparisons (Wolters Kluwer, Philadelphia, PA, USA) were used to confirm prescription and OTC status. In the event that a medication on a patient's list did not contain a corresponding strength or had a missing frequency, the medication was not included in pMRCI scoring. As a surrogate for concomitant disease states, each drug was also assigned a therapeutic drug class using Micromedex Solutions and Facts \& Comparisons.

\section{Data analysis}

Data were analyzed with SPSS software version 23 (IBM, New York, NY, USA). Descriptive statistics were generated and data expressed as number (\%), mean, standard deviation, and/or range. Total and subsection pMRCI scores were analyzed as continuous variables, while medication counts were analyzed as both continuous and categorical variables (ie, 0-10 medications, 11-15 medications, and $\geq 16$ medications). Categorical data were compared between groups using $\chi^{2}$ or Fisher's exact tests. Pearson correlations were used to assess the relationship between variables (eg, pMRCI score and medication count; pMRCI score and sex). Data were compared between age groups (young-old versus old-old) using general linear model analysis, with heart failure etiology (NISCM versus ISCM), New York Heart Association (NYHA) functional class, and sex as covariates. Data were also compared based on heart failure etiology (NISCM versus ISCM) using general linear model analysis, with NYHA functional class and sex as covariates. A $P$-value $<0.05$ was used as the level of significance.

\section{Results}

\section{Patient demographics}

The study included 145 patients (64.1\% men, 35.9\% women, mean age $73 \pm 8$ years, range 61-89 years). Age was categorized as young-old (60-74 years, $n=80$ [55.2\%]) and old-old (75-89 years, $n=65$ [44.8\%]). The racial distribution was $80.7 \%$ Caucasian, 10.3\% African-American, 2.1\% Asian/Pacific Islander, and $6.9 \%$ other; $4.8 \%$ of patients classified their ethnicity as Hispanic. There were 60 patients (41.4\%) with NISCM and 85 patients (58.6\%) with ISCM. The percentage of patients with NYHA functional class I, II, III, and IV heart failure was $16.6 \%, 27.6 \%, 27.6 \%$, and $28.3 \%$, respectively.

\section{Medication regimen complexity in all patients}

In the entire study cohort, the mean total medication count was $13.3 \pm 4.8$ (range 2-30) and the mean total pMRCI score was $32.1 \pm 14.4$ (range 3-84). The percentage of patients taking $0-10,11-15$, or $\geq 16$ total medications was $28 \%, 43 \%$, and $29 \%$, respectively. Of note, there was only one patient in the cohort taking fewer than five medications. Conversely, there were three patients in the cohort taking 25 or more medications. Total medication count was significantly correlated with total pMRCI score $(r=0.85, P<0.001)$, heart failure etiology (ISCM vs NISCM, $r=0.19 ; P=0.02$ ), and NYHA functional class ( $r=0.17, P=0.04)$, but not age, sex, or race (data not shown). Similar significant correlations were observed between total pMRCI score and heart failure etiology $(r=0.19, P=0.02)$ and NYHA functional class $(r=0.18, P=0.03)$.

Heart failure prescriptions, other prescriptions, and OTC medications accounted for $24 \%, 50 \%$, and $26 \%$ of the total medication count, respectively, and $22 \%, 56 \%$, and $22 \%$ of the total pMRCI score, respectively (Table 1). Of the pMRCI subsections (ie, dosage form, dosing frequency, or additional directions), dosing frequency accounted for the majority 
Table I Summary of medication regimen complexity in the overall heart failure cohort

\begin{tabular}{|c|c|}
\hline Medication variable & Overall cohort $(n=145)$ \\
\hline Total medication count & $13.3 \pm 4.8(2-30)$ \\
\hline Heart failure prescription count & $3.2 \pm 1.3(0-7)$ \\
\hline Percentage of total medication count & $24 \%$ \\
\hline Other prescription count & $6.6 \pm 3.6(0-17)$ \\
\hline Percentage of total medication count & $50 \%$ \\
\hline OTC medication count & $3.5 \pm 2.4(0-19)$ \\
\hline Percentage of total medication count & $26 \%$ \\
\hline Total pMRCI score & $32.1 \pm 14.4(3-84)$ \\
\hline Heart failure prescription pMRCI score & $7.2 \pm 3.4(0-15)$ \\
\hline Percentage of total pMRCl score & $22 \%$ \\
\hline Other prescription pMRCl score & $18 \pm 11.9(0-60)$ \\
\hline Percentage of total pMRCl score & $56 \%$ \\
\hline OTC medication pMRCI score & $6.9 \pm 4.9(0-34.5)$ \\
\hline Percentage of total pMRCl score & $22 \%$ \\
\hline \multicolumn{2}{|l|}{$\mathrm{pMRCl}$ subsection scores } \\
\hline Dosage-form subsection score & $7 \pm 4.5(I-26)$ \\
\hline Percentage of total pMRCl score & $21.8 \%$ \\
\hline Frequency subsection score & 19.8土9.3 (2-57.5) \\
\hline Percentage of total $\mathrm{pMRCl}$ score & $61.6 \%$ \\
\hline Additional directions subsection score & $5.3 \pm 3.1(0-15)$ \\
\hline Percentage of total pMRCI score & $16.5 \%$ \\
\hline
\end{tabular}

Note: Data expressed as mean \pm standard deviation (range) or percentages. Abbreviations: OTC, over-the-counter; pMRCl, patient-level Medication Regimen Complexity Index.

(61.6\%) of the total pMRCI score. The most commonly prescribed heart failure medications were $\beta$-blockers ( $76.6 \%$ of patients), loop diuretics ( $66.2 \%$ of patients), aldosterone antagonists (60.7\% of patients), ACE inhibitors/angiotensinreceptor blockers (57.2\% of patients), and digoxin (32.4\% of patients). Percentages do not total $100 \%$, as patients could be taking medications from multiple classes. The most common other prescriptions were statins ( $64.1 \%$ of patients), anticoagulants (51\% of patients), proton pump inhibitors (38.6\% of patients), potassium supplements (28.3\% of patients), and thyroid supplements ( $27.6 \%$ of patients). The most common OTC medications were aspirin ( $66.9 \%$ of patients), vitamin D ( $29 \%$ of patients), multivitamins ( $27.6 \%$ of patients), calcium (20.7\% of patients), fish oil (20.7\% of patients), and acetaminophen ( $20.7 \%$ of patients).

\section{Comparisons of medication regimen complexity}

To address the primary objective, medication regimen complexity was compared between young-old versus oldold patients, with heart failure etiology, NYHA functional class, and sex as covariates (Table 2). Medication counts and pMRCI scores did not differ significantly between the age groups, with the exception of OTC pMRCI score, which
Table 2 Comparison of demographic variables and medication regimen complexity between young-old (60-74 years) and old-old (75-89 years) patients with heart failure

\begin{tabular}{|c|c|c|c|}
\hline Medication variable & $\begin{array}{l}\text { Young-old } \\
(n=80)\end{array}$ & $\begin{array}{l}\text { Old-old } \\
(n=65)\end{array}$ & $P$-value \\
\hline \multicolumn{4}{|l|}{ Demographics } \\
\hline Age, years & $67 \pm 4$ & $80 \pm 4$ & $<0.001$ \\
\hline Men & $46(57.5 \%)$ & 47 (72.3\%) & 0.06 \\
\hline Caucasian & $64(80 \%)$ & $53(81.5 \%)$ & 0.82 \\
\hline Hispanic & $5(6.3 \%)$ & $2(3.1 \%)$ & 0.46 \\
\hline \multicolumn{4}{|l|}{ Heart failure etiology } \\
\hline NISCM & $39(48.8 \%)$ & $21(32.3 \%)$ & 0.05 \\
\hline ISCM & $4 \mathrm{I}(5 \mathrm{I} .3 \%)$ & $44(67.7 \%)$ & \\
\hline \multicolumn{4}{|l|}{ NYHA functional class } \\
\hline I & $13(16.3 \%)$ & II (I6.9\%) & 0.96 \\
\hline II & $22(27.5 \%)$ & $18(27.7 \%)$ & \\
\hline III & $21(26.3 \%)$ & $19(29.2 \%)$ & \\
\hline IV & $24(30 \%)$ & $17(26.2 \%)$ & \\
\hline Total medication count & $13.2 \pm 4.8$ & $13.5 \pm 4.8$ & 0.68 \\
\hline Heart failure prescription count & $3.2 \pm 1.2$ & $3.2 \pm 1.4$ & 0.85 \\
\hline $\begin{array}{l}\text { Percentage of total medication } \\
\text { count }\end{array}$ & $24 \%$ & $23 \%$ & \\
\hline Other prescription count & $6.7 \pm 3.7$ & $6.6 \pm 3.5$ & 0.69 \\
\hline $\begin{array}{l}\text { Percentage of total medication } \\
\text { count }\end{array}$ & $51 \%$ & $49 \%$ & \\
\hline ОTC medication count & $3.3 \pm 2.1$ & $3.8 \pm 2.7$ & 0.13 \\
\hline $\begin{array}{l}\text { Percentage of total medication } \\
\text { count }\end{array}$ & $25 \%$ & $28 \%$ & \\
\hline Total pMRCI score & $31.7 \pm 14.3$ & $32.7 \pm 14.7$ & 0.66 \\
\hline $\begin{array}{l}\text { Heart failure prescription } \mathrm{pMRCl} \\
\text { score }\end{array}$ & $7.5 \pm 3.3$ & $6.9 \pm 3.5$ & 0.37 \\
\hline Percentage of total $\mathrm{pMRCl}$ score & $24 \%$ & $21 \%$ & \\
\hline Other prescription pMRCI score & $18 \pm 12$ & $18 \pm 11.9$ & 0.96 \\
\hline Percentage of total $\mathrm{pMRCl}$ score & $57 \%$ & $55 \%$ & \\
\hline OTC medication pMRCI score & $6.2 \pm 4$ & $7.8 \pm 5.8$ & 0.04 \\
\hline Percentage of total pMRCI score & $19 \%$ & $24 \%$ & \\
\hline \multicolumn{4}{|l|}{ Medication categories } \\
\hline On 0-10 total medications & $23(28.8 \%)$ & I8 (27.7\%) & 0.97 \\
\hline On $11-15$ total medications & 35 (43.8\%) & $28(43.1 \%)$ & \\
\hline On $\geq 16$ total medications & $22(27.5 \%)$ & $19(29.2 \%)$ & \\
\hline
\end{tabular}

Notes: Data expressed as mean \pm standard deviation or $\mathrm{n}(\%)$. Medication counts and PMRCl scores were compared between groups using generalized linear model analysis, with heart failure etiology (ISCM vs NISCM), NYHA functional class, and sex as covariates.

Abbreviations: ISCM, ischemic cardiomyopathy; NISCM, nonischemic cardiomyopathy; NYHA, New York Heart Association; OTC, over-the-counter; PMRCl, patient-level Medication Regimen Complexity Index.

was significantly higher in old-old than young-old patients (7.8 \pm 5.8 vs $6.2 \pm 4, P=0.04$ ). For the secondary objective, medication regimen complexity was also compared between patients with NISCM and ISCM, with NYHA functional class and sex as covariates (Table 3 ). There were more Caucasians in the ISCM group than in the NISCM group; however, race was not significantly associated with medication counts or pMRCI scores, and was thus not included as a covariate in 
Table 3 Comparison of demographic variables and medication regimen complexity between patients with nonischemic cardiomyopathy versus ischemic cardiomyopathy

\begin{tabular}{|c|c|c|c|}
\hline & $\begin{array}{l}\text { NISCM } \\
(n=60)\end{array}$ & $\begin{array}{l}\begin{array}{l}\text { ISCM } \\
(n=85)\end{array} \\
\end{array}$ & $P$-value \\
\hline \multicolumn{4}{|l|}{ Demographics } \\
\hline Age, years & $7 I \pm 7$ & $74 \pm 8$ & 0.05 \\
\hline Men & $32(53.3 \%)$ & 61 (7I.8\%) & 0.02 \\
\hline Caucasian & $43(71.7 \%)$ & $74(87 \%)$ & 0.02 \\
\hline Hispanic & $3(5 \%)$ & $4(4.7 \%)$ & 1 \\
\hline \multicolumn{4}{|l|}{ NYHA functional class } \\
\hline I & $16(26.7 \%)$ & $8(9.4 \%)$ & 0.03 \\
\hline II & $13(21.7 \%)$ & $27(31.8 \%)$ & \\
\hline III & $13(21.7 \%)$ & $27(31.8 \%)$ & \\
\hline IV & $18(30 \%)$ & $23(27 \%)$ & \\
\hline Total medication count & $12.2 \pm 4.5$ & $\mid 4.1 \pm 4.9$ & 0.008 \\
\hline Heart failure prescription count & $3.2 \pm 1.2$ & $3.2 \pm 1.4$ & 0.51 \\
\hline $\begin{array}{l}\text { Percentage of total medication } \\
\text { count }\end{array}$ & $26 \%$ & $23 \%$ & \\
\hline Other prescription count & $5.7 \pm 3.7$ & $7.3 \pm 3.4$ & 0.008 \\
\hline $\begin{array}{l}\text { Percentage of total medication } \\
\text { count }\end{array}$ & $47 \%$ & $52 \%$ & \\
\hline OTC medication count & $3.3 \pm 2$ & $3.6 \pm 2.6$ & 0.37 \\
\hline $\begin{array}{l}\text { Percentage of total medication } \\
\text { count }\end{array}$ & $27 \%$ & $25 \%$ & \\
\hline Total pMRCI score & $28.8 \pm 12.7$ & $34.5 \pm 15.2$ & 0.009 \\
\hline Heart failure prescription & $7.3 \pm 3.4$ & $7.2 \pm 3.4$ & 0.99 \\
\hline \multicolumn{4}{|l|}{ pMRCI score } \\
\hline Percentage of total pMRCl score & $25 \%$ & $21 \%$ & \\
\hline Other prescription pMRCI score & $|5.4 \pm| \mid .5$ & $19.8 \pm 12$ & 0.02 \\
\hline Percentage of total pMRCI score & $53 \%$ & $57 \%$ & \\
\hline OTC medication pMRCI score & $6.1 \pm 3.5$ & $7.5 \pm 5.6$ & 0.05 \\
\hline Percentage of total pMRCl score & $22 \%$ & $22 \%$ & \\
\hline \multicolumn{4}{|l|}{ Categories } \\
\hline On $0-10$ total medications & $21(35 \%)$ & $20(23.5 \%)$ & 0.07 \\
\hline On $11-15$ total medications & $28(46.7 \%)$ & 35 (4I.1\%) & \\
\hline On $\geq 16$ total medications & $\mathrm{II}(\mathrm{I} 8.3 \%)$ & 30 (35.3\%) & \\
\hline
\end{tabular}

Notes: Data expressed as mean \pm standard deviation or $\mathrm{n}(\%)$. Medication counts and $\mathrm{pMRCl}$ scores were compared between groups using generalized linear model analysis, with NYHA functional class and sex as covariates.

Abbreviations: ISCM, ischemic cardiomyopathy; NISCM, nonischemic cardiomyopathy; NYHA, New York Heart Association; OTC, over-the-counter pMRCl, patient-level Medication Regimen Complexity Index.

the analysis. Total medication count was significantly higher in patients with ISCM than NISCM (14.1 \pm 4.9 vs $12.2 \pm 4.5$, $P=0.008$ ), which was primarily driven by differences in the number of other prescriptions ( $7.3 \pm 3.4$ vs $5.7 \pm 3.7, P=0.008)$. Total pMRCI score was also significantly higher in patients with ISCM than NISCM (34.5 \pm 15.2 vs $28.8 \pm 12.7, P=0.009)$. This was a result of higher other prescription and OTC medication pMRCI scores in the ISCM group than the NISCM group. The frequencies of the other major prescription-drug classes that were significantly higher in patients with ISCM vs NISCM were statins, calcium channel blockers, antiarrhythmics, nonaspirin antiplatelet agents, and topical corticosteroids (data not shown).

\section{Discussion}

Our retrospective study quantified medication regimen complexity in older adults with heart failure in the ambulatory setting using the pMRCI tool. Medication regimen complexity did not differ significantly in old-old versus young-old patients. However, total medication counts and pMRCI scores were significantly higher in patients with ISCM compared with NISCM. This finding is not surprising, as patients with ISCM have a greater burden of comorbidities, such as hypertension, angina, diabetes, peripheral vascular disease, renal dysfunction, and hyperlipidemia, compared to those with NISCM. ${ }^{45}$ These comorbidities contribute additional drugs to the pharmacotherapeutic treatment regimen and increase the total pMRCI score. Together, our data highlight the substantial medication burden associated with heart failure, especially in older adults, and reveal multiple opportunities to address polypharmacy in this population.

Polypharmacy is a major risk factor for medication nonadherence, and $72 \%$ of the patients in our ambulatory cohort were taking eleven or more medications. ${ }^{5,24}$ From a public health perspective, this finding is of considerable importance, as the probability of an adverse drug reaction increases to $82 \%$ when seven or more medications are prescribed. ${ }^{46}$ To date, most assessments of medication regimen complexity in heart failure patients have been conducted in the hospital setting. ${ }^{36,38,39}$ For example, Yam et al reported a mean pMRCI score and medication count of $35.5 \pm 19$ and $12.9 \pm 6.3$, respectively, at the time of hospital admission in a predominantly male $(97 \%)$ cohort of US veterans with heart failure. Our findings are consistent with these data, and indicate that high treatment burden extends to a more heterogeneous population of heart failure patients ( $64 \%$ men) in the ambulatory setting. When we compare our findings to pMRCI studies in other disease states, older adults with heart failure have higher medication regimen complexity and/or medication counts than patients with heart transplant, depression, HIV, diabetes, and hypertension. ${ }^{28,30,31,33,35}$ For example, in our previous work with heart transplant recipients, the mean pMRCI score was $30.4 \pm 7$ and mean medication count was $13.5 \pm 3.2$ at 1 year posttransplant. ${ }^{31}$ Therefore, older adults with heart failure are likely to be among the "highest-risk" patients, on par with heart transplant recipients, in terms of medication regimen complexity.

It has been suggested that simpler methods to evaluate medication regimen complexity, eg, medication count, are needed in the clinical setting. We observed a strong correlation between total medication count and total pMRCI score in older adults with heart failure. However, $28 \%$ of the 
variability in pMRCI scores was not explained by medication count alone. As the evaluation of medication complexity continues to be documented in the literature and linked to clinical outcomes, the pMRCI may be a useful tool to identify patients for more enhanced medication-therapy management interventions, such as those by a pharmacist. ${ }^{29,47}$ Along these lines, a clinical science statement from the American Heart Association addressing medications that can exacerbate or cause heart failure suggested that while not currently associated with improved outcomes, the use of medicationcomplexity tools should be considered in potentially reducing polypharmacy (class IIA, level of evidence C). ${ }^{48}$

There are several limitations of our study that deserve to be acknowledged. We retrospectively evaluated medication lists from the electronic medical record; therefore, we could not assess medication adherence. The retrospective design and electronic data collection also precluded the ability to capture "additional instructions" that were given to the patient verbally or in writing at the time of the clinic visit. We did not compare pMRCI scores between those with heart failure with reduced ejection fraction versus heart failure with preserved ejection fraction, as these classifications were not consistently documented in the clinical notes during the study time period (eg, recent echocardiograms were not always available in relation to the patient's most recent medication list). Along the same lines, our retrospective study included only patients who had a heart failure diagnosis in the electronic medical record, possibly missing qualifying patients who were sick, yet did not have an established heart failure diagnosis. Our study consisted of patients from one heart failure clinic, and may not accurately address prescribing patterns across different clinics or regions. The study sample size was also relatively small; however, post hoc power analysis revealed that this sample size provided $80 \%$ power to detect a clinically meaningful difference of 2.3 medications between the young-old and old-old groups and a 6.8-point difference in pMRCI score, a moderate-to-large effect.

It is important to note that the pMRCI tool does not take into account other factors that may contribute to medication regimen complexity in older adults, such as vision impairment, decreased manual dexterity, cognitive impairment, patient-education level, patient perceptions of treatment burden, and socioeconomic status (eg, insurance coverage). ${ }^{49}$ While NYHA functional class was included as a covariate in statistical analysis, assessment of the severity of other comorbidities and the contribution to medication regimen complexity was not evaluated in this retrospective electronic medical record review. We also did not assess the relationship between medication regimen complexity and clinical outcomes (eg, hospitalizations for heart failure) in this cohort, and further research in this area is warranted.

\section{Conclusion}

Medication regimen complexity is high in older adults with heart failure, and differs based on disease etiology. Opportunities exist for pharmacists and other health care professionals to address polypharmacy and medication regimen complexity in patients with heart failure, which may include extended counseling for patients and caregivers, frequent patient follow-up, simplification of medication regimens (eg, evaluation of the necessity of OTC agents), and clinic-based adherence assessments. Additional studies are needed to address the impact of these interventions on clinical outcomes in older adults with heart failure.

\section{Disclosure}

This work was presented in part as a poster presentation at the International Society for Heart and Lung Transplantation 36th Annual Meeting and Scientific Sessions, April 27-30, 2016, Washington, DC. ${ }^{50}$ The authors report no conflicts of interest in this work.

\section{References}

1. Heidenreich PA, Albert NM, Allen LA, et al. Forecasting the impact of heart failure in the United States: a policy statement from the American Heart Association. Circ Heart Fail. 2013;6(3):606-619.

2. Mozaffarian D, Benjamin EJ, Go AS, et al. Heart disease and stroke statistics - 2015 update: a report from the American Heart Association. Circulation. 2015;131(4):e29-e322.

3. Ziaeian B, Fonarow GC. Epidemiology and aetiology of heart failure. Nat Rev Cardiol. 2016;13(6):368-378.

4. Massie BM, Shah NB. Evolving trends in the epidemiologic factors of heart failure: rationale for preventive strategies and comprehensive disease management. Am Heart J. 1997;133(6):703-712.

5. Riles EM, Jain AV, Fendrick AM. Medication adherence and heart failure. Curr Cardiol Rep. 2014;16(3):458.

6. Braunwald E. The war against heart failure: the Lancet lecture. Lancet. 2015;385(9970):812-824.

7. Yancy CW, Jessup M, Bozkurt B, et al. 2013 ACCF/AHA guideline for the management of heart failure: a report of the American College of Cardiology Foundation/American Heart Association Task Force on practice guidelines. Circulation. 2013;128(16):e240-e327.

8. Yancy CW, Jessup M, Bozkurt B, et al. 2016 ACC/AHA/HFSA focused update on new pharmacological therapy for heart failure - an update of the 2013 ACCF/AHA guideline for the management of heart failure: a report of the American College of Cardiology/American Heart Association Task Force on Clinical Practice Guidelines and the Heart Failure Society of America. Circulation. 2016;22(9):659-669.

9. Braunstein JB, Anderson GF, Gerstenblith G, et al. Noncardiac comorbidity increases preventable hospitalizations and mortality among Medicare beneficiaries with chronic heart failure. $\mathrm{J} \mathrm{Am} \mathrm{Coll} \mathrm{Cardiol}$. 2003;42(7):1226-1233.

10. Page RL 2nd, Lindenfeld J. The comorbidity conundrum: a focus on the role of noncardiovascular chronic conditions in the heart failure patient. Curr Cardiol Rep. 2012;14(3):276-284. 
11. Lazzarini V, Mentz RJ, Fiuzat M, Metra M, O’Connor CM. Heart failure in elderly patients: distinctive features and unresolved issues. Eur J Heart Fail. 2013;15(7):717-723.

12. Masoudi FA, Baillie CA, Wang Y, et al. The complexity and cost of drug regimens of older patients hospitalized with heart failure in the United States, 1998-2001. Arch Intern Med. 2005;165(18):2069-2076.

13. Qato DM, Alexander GC, Conti RM, Johnson M, Schumm P, Lindau ST. Use of prescription and over-the-counter medications and dietary supplements among older adults in the United States. JAMA. 2008;300(24):2867-2878.

14. Gnjidic D, Hilmer SN, Blyth FM, et al. Polypharmacy cutoff and outcomes: five or more medicines were used to identify communitydwelling older men at risk of different adverse outcomes. J Clin Epidemiol. 2012;65(9):989-995.

15. Mastromarino V, Casenghi M, Testa M, et al. Polypharmacy in heart failure patients. Curr Heart Fail Rep. 2014;11(2):212-219.

16. Qato DM, Wilder J, Schumm LP, Gillet V, Alexander GC. Changes in prescription and over-the-counter medication and dietary supplement use among older adults in the United States, 2005 vs 2011. JAMA Intern Med. 2016;176(4):473-482.

17. Wu JR, Moser DK, Lennie TA, Burkhart PV. Medication adherence in patients who have heart failure: a review of the literature. Nurs Clin North Am. 2008;43(1):133-153; vii-viii.

18. Horwitz RI, Viscoli CM, Berkman L, et al. Treatment adherence and risk of death after a myocardial infarction. Lancet. 1990;336(8714): 542-545.

19. Ho KK, Pinsky JL, Kannel WB, Levy D. The epidemiology of heart failure: the Framingham Study. J Am Coll Cardiol. 1993;22(4 Suppl A): 6A-13A

20. Michalsen A, König G, Thimme W. Preventable causative factors leading to hospital admission with decompensated heart failure. Heart. 1998;80(5):437-441.

21. Fitzgerald AA, Powers JD, Ho PM, et al. Impact of medication nonadherence on hospitalizations and mortality in heart failure. J Card Fail. 2011;17(8):664-669.

22. George J, Phun YT, Bailey MJ, Kong DC, Stewart K. Development and validation of the Medication Regimen Complexity Index. Ann Pharmacother. 2004;38(9):1369-1376.

23. Paquin AM, Zimmerman KM, Kostas TR, et al. Complexity perplexity: a systematic review to describe the measurement of medication regimen complexity. Expert Opin Drug Saf. 2013;12(6):829-840.

24. Mansur N, Weiss A, Beloosesky Y. Looking beyond polypharmacy: quantification of medication regimen complexity in the elderly. Am J Geriatr Pharmacother. 2012;10(4):223-229.

25. Neri L, Martini A, Andreucci VE, Gallieni M, Rey LA, Brancaccio D Regimen complexity and prescription adherence in dialysis patients. Am J Nephrol. 2011;34(1):71-76.

26. Schoonover H, Corbett CF, Weeks DL, Willson MN, Setter SM Predicting potential postdischarge adverse drug events and 30-day unplanned hospital readmissions from medication regimen complexity. J Patient Saf. 2014;10(4):186-191.

27. Willson MN, Greer CL, Weeks DL. Medication regimen complexity and hospital readmission for an adverse drug event. Ann Pharmacother. 2014;48(1):26-32.

28. Libby AM, Fish DN, Hosokawa PW, et al. Patient-level medication regimen complexity across populations with chronic disease. Clin Ther. 2013;35(4):385-398.e1.

29. Hirsch JD, Metz KR, Hosokawa PW, Libby AM. Validation of a patient-level medication regimen complexity index as a possible tool to identify patients for medication therapy management intervention. Pharmacotherapy. 2014;34(8):826-835

30. Linnebur SA, Vande Griend JP, Metz KR, Hosokawa PW, Hirsch JD, Libby AM. Patient-level medication regimen complexity in older adults with depression. Clin Ther. 2014;36(11):1538-1546.e1.

31. Bryant BM, Libby AM, Metz KR, et al. Evaluating patient-level medication regimen complexity over time in heart transplant recipients. Ann Pharmacother. 2016;50(11):926-934.
32. Kamila P, Smith SG, Patzer R, Wolf MS, Marina S. Medication regimen complexity in kidney and liver transplant recipients. Transplantation. 2014;98(7):e73-e74.

33. Rettig SM, Wood Y, Hirsch JD. Medication regimen complexity in patients with uncontrolled hypertension and/or diabetes. J Am Pharm Assoc (2003). 2013;53(4):427-431.

34. McDonald MV, Peng TR, Sridharan S, et al. Automating the medication regimen complexity index. J Am Med Inform Assoc. 2013;20(3): 499-505.

35. Metz KR, Fish DN, Hosokawa PW, Hirsch JD, Libby AM. Patientlevel medication regimen complexity in patients with HIV. Ann Pharmacother. 2014;48(9):1129-1137.

36. Yam FK, Lew T, Eraly SA, Lin HW, Hirsch JD, Devor M. Changes in medication regimen complexity and the risk for 90-day hospital readmission and/or emergency department visits in U.S. veterans with heart failure. Res Social Adm Pharm. 2016;12(5):713-721.

37. Ghimire S, Peterson GM, Castelino RL, Jose MD, Zaidi ST. Medication regimen complexity and adherence in haemodialysis patients: an exploratory study. Am J Nephrol. 2016;43(5):318-324.

38. Abou-Karam N, Bradford C, Lor KB, Barnett M, Ha M, Rizos A. Medication regimen complexity and readmissions after hospitalization for heart failure, acute myocardial infarction, pneumonia, and chronic obstructive pulmonary disease. SAGE Open Med. 2016;4: 2050312116632426

39. Colavecchia AC, Putney DR, Johnson ML, Aparasu RR. Discharge medication complexity and 30-day heart failure readmissions. Res Social Adm Pharm. Epub 2016 Oct 8.

40. Wimmer BC, Dent E, Bell JS, et al. Medication regimen complexity and unplanned hospital readmissions in older people. Ann Pharmacother. 2014;48(9):1120-1128.

41. Wimmer BC, Johnell K, Fastbom J, Wiese MD, Bell JS. Factors associated with medication regimen complexity in older people: a crosssectional population-based study. Eur J Clin Pharmacol. 2015;71(9): 1099-1108.

42. Wimmer BC, Bell JS, Fastbom J, Wiese MD, Johnell K. Medication regimen complexity and number of medications as factors associated with unplanned hospitalizations in older people: a population-based cohort study. J Gerontol A Biol Sci Med Sci. 2016;71(6):831-837.

43. Lalic S, Jamsen KM, Wimmer BC, et al. Polypharmacy and medication regimen complexity as factors associated with staff informant rated quality of life in residents of aged care facilities: a cross-sectional study. Eur J Clin Pharmacol. 2016;72(9):1117-1124.

44. Lalic S, Sluggett JK, Ilomäki J, et al. Polypharmacy and medication regimen complexity as risk factors for hospitalization among residents of long-term care facilities: a prospective cohort study. J Am Med Dir Assoc. 2016;17(11):1067.e1-1067.e6.

45. Felker GM, Shaw LK, O'Connor CM. A standardized definition of ischemic cardiomyopathy for use in clinical research. J Am Coll Cardiol. 2002;39(2):210-218.

46. Goldberg RM, Mabee J, Chan L, Wong S. Drug-drug and drug-disease interactions in the ED: analysis of a high-risk population. Am J Emerg Med. 1996;14(5):447-450.

47. Clay PG. Medication regimen complexity indices: a tool to focus MTM efforts? J Am Pharm Assoc (2003). 2014;54(6):664.

48. Page RL 2nd, O'Bryant CL, Cheng D, et al. Drugs that may cause or exacerbate heart failure: a scientific statement from the American Heart Association. Circulation. 2016;134(6):e32-e69.

49. Corsonello A, Pedone C, Lattanzio F, et al. Regimen complexity and medication nonadherence in elderly patients. Ther Clin Risk Manag. 2009;5(1):209-216.

50. Cobretti MR, Deininger KM, Linnebur SA, Page RL, Lindenfeld J, Aquilante CL. Medication regimen complexity in older adults with heart failure. J Heart Lung Transplant. 2016;35(4 Suppl):S419-S420. 


\section{Publish your work in this journal}

Clinical Interventions in Aging is an international, peer-reviewed journal focusing on evidence-based reports on the value or lack thereof of treatments intended to prevent or delay the onset of maladaptive correlates of aging in human beings. This journal is indexed on PubMed Central, MedLine,

CAS, Scopus and the Elsevier Bibliographic databases. The manuscript management system is completely online and includes a very quick and fair peer-review system, which is all easy to use. Visit http://www.dovepress. com/testimonials.php to read real quotes from published authors. 